\title{
Online learning sa panahon ng pandemya
}

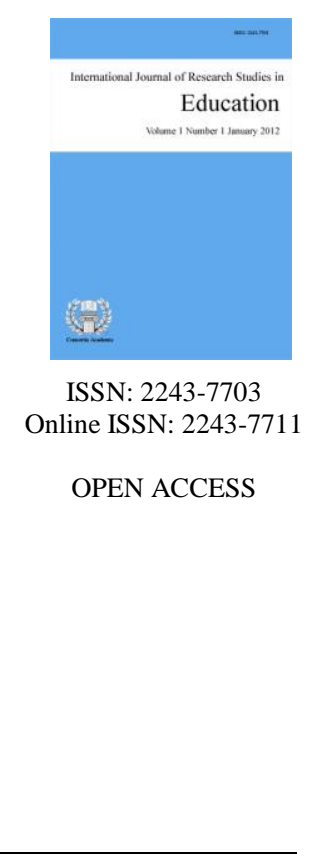

Jazo, Kathleen Mae

Veritas College of Irosin, Philippines

Borlagdan, Jessica

Veritas College of Irosin, Philippines

Fernicol, Joysie

Veritas College of Irosin, Philippines

Rivero, Jerome

Veritas College of Irosin, Philippines

Gelilio, Eric $\square$

Veritas College of Irosin, Philippines

Sorsogon State University, Philippines

Gallanosa National High School, Philippines (gelilioeric@gmail.com)

Received: 30 January 2022

Available Online: 7 February 2022

Revised: 5 February 2022 DOI: $10.5861 /$ ijrse. 2022.138

Accepted: 7 February 2022

\section{Abstract}

This study identified the number of students experiencing the impact of online learning due to the pandemic period. Through purposive sampling, fifty participants were obtained from the town of Irosin. And using the descriptive method of gathering information the various effects of online learning are determined whether affective or positive. Based on the survey gathered $50 \%$ of the students have difficulty keeping up while $50 \%$ agree with online learning. According to Hanushek and Woessman (2020) the sudden change in the use of digital teaching can occur with sub-optimal results, comparable to a business. In this study it is reflected that it is in the hands of teachers and mag- studying the continuity of education in modern ways and times. This study found that the effect of online learning is not negative but comfort to parents and student. By embracing the true meaning of education, learning is much easier, with a solid foundation attached. It will be the way to fulfill the meaning and every dream of the student even if we are faced with pandemic.

Keywords: online learning, impacts. descriptive method, Irosin, survey 


\section{Online learning sa panahon ng pandemya}

\section{Introduksyon}

Alinsunod sa ilalim ng RA 10650, ang open distance learning sa pilipinas para sa mas mataas na edukasyon (HEIs). At teknikal bokasyonal na kurso ay may layuning magbigay ng naa-access, dekalidad na edukasyon sa pamamagitan ng "Open Educational Learning Materials" (OER) at paghahatid ng learning materials sa pamamagitan ng print, audio-visual, electronic/computer at virtual na silid-aralan, at mga sesyon ng harapan. Ang komisyon sa mataas na edukasyon (CHED) ay nag-utos sa mga HEIsi (Health Education Systems Incorporated) na magdeploy ng available na pag-aaral ng distansya, e-learning, at iba pang alternatibong paraan ng paghahatid bilang kapalit ng pag-aaral sa tirahan kung meron silang mga mapagkukunan upang gawin ito. Ipagpapatuloy ng HESi ang kanilang paghuhusga sa paglalagay ng ginagamit na flexible ns pag-aaral at iba pang alternatibong paraan ng paghahatid bilang kapalit ng pag-aaral sa loob ng kampus na meron silang mga mapagkukunan upang gawin ito. Angpagpapalakas ng online na pag-aaral kapag ang mga paaralan ay sarado: ang papel ng mga pamilya at guro sa pagsuporta sa mga mag-aaral sa panahon ng COVID-19 ayon sa tugon sa patakaran ng OECD (Organisation for Economic Co-Operation and Development) sa coronavirus (COVID-19) noong Setyembre 24,2020). Bilang tugon sa krisis sa COVID-19 maraming bansa sa buong mundo ang nagsara ng mga paaralan, kolehiyo at mga unibersidad upang pigilan ang pagkalat ng virus.Alinsunod mula sa datos ng UNESCO (United Nations Educational, Scientific and Cultural Organization), ang tugatog sa mga pagsasara ng paaralan ay nairehistro noong simula ng Abril 2020, nang mga 1.6 bilyon na nag-aaral ang naapektuhan sa 194 na bansa,na nagkakahalaga ng higit sa $90 \%$ ng kabuuang mga naka-enroll na mag-aaral alinsunod sa (UNESCO).

Ang biglaang pagsasara ng mga paaralan ay nangangahulugan na mga gumagawa ng patakaran sa edukasyon mga punong-guro ng paaralan at mga guro ay kailangang maghanap ng mga alternatibo sa harapang pagtuturo upang magarantiya ang karapatan ng mga bata sa edukasyon. Maraming sistema ang nagpatibay ng online na pagtuturo at sa pag-aaral sa isang hindi pa nagagawa ng sukat, kadalasang kasabay ng malawakang malayong pag-aaral na materyales gaya ng telebisyon o radyo. Hanggang sa maging available ang mga epektibong bakuna o "therapeutics" para sa novel coronavirus, malamang na patuloy na maabala ang pag-aaral, kahit na ang pinakamasamang sitwasyon ng isang pangalawang alon ng pagsiklab ay hindi natin dapat gawin, ang mga lokal at pansamantalang pagsasara ng paaralan ay maaaring kailanganin pa rin ng mapigilan ang paghahatid ng COVID-19. Halimbawa, ng mga batang nakikipag ugnayan sa mga nahawaang indibidwal ay maaaring kailanganin sa sarili. Ibukod at ang kakulangan ng sapat na mga puwang para makadalo sila sa mga klase ang mga kwalipikasyon tagapagturo ng ipapakalat sa mga sitwasyong iyon ay mapipilitan ang ilang mga paaralan na magpatibay ng mga pinaghalong modelo upang magarantiya ang pagdistansya mula sa ibang tao.

Ayon kay (Burgess, 2020); ito ay nangyari na, halimbawa sa Germany, kung saan dalawang linggo lamang pagkatapos ng muling pagbubukas,ng ilang paaralan anang muling isinara dahil sa impeksyon sa coronavirus laban sa "uncertion backdrop" na ito.Samakatuwid ay mahalagang tukuyin kung aling mga patakaran ang maaaring mapakinabangan ang pagiging epektibo ng online na pagtuturo at pag -aaral sa kabila ng pagiging isang kanais-nais na opsyon kumpara sa walang pag-aaral na maaaring magdulot ng malaking pagkaantala sa pag-aaral. Ayon kina Hanushek at Woessmann (2020), ang biglaang paglipat sa paggamit ng digital na pagtuturo ay maaaring humantong sa mga "sub-optimal"na resulta kung ihahambing sa isang negosyo gaya ng nakagawian sa presensya na pagtuturo dahil ang mga guro, mag-aaral at paaralan ay kailangang iangkop sa isang bagong sitwasyon. Marami din mga paraan ang pwedeng magamit sa digital na pagtuturo (Ching at Roberts, 2021). Madami na din ang sumubok na gamitin ang iba-ibang pamaraan sa digital na pagtuturo (Castroverde at Acala, 2021; Bullo, 2021; Llaneta, 2021) at madami pang iba. Sinusuri ng mabuti ang patakaran ng ilan sa mga paghihirap upang maunawaan kung paano mas mapapabuti pa ang malayong pag-aaral kung kinakailangan ang online na pag-aaral upang maiwasan ang malawakang paghahatid. Ang pangalawang alalahin ay ang ilang mga 
mag-aaral ay hindi nakatanggap ng sapat na bilang ng mga oras ng pagtuturo.

Halimbawa sa United Kingdom, 71\% ng mga batang paaralan ng estado ang nakatanggap ng hindi o mas mababa sa isang araw-araw na online na aralin, habang ang Germany at 6\% lamang ang mga mag-aaral ang nakaonline araw-araw. At higit sa kalahati ang nagkaroon ng mga ito. Mas mababa sa isang beses sa isang linggo ayon kay (Woessmann et al., 2020). Tinantiya ng ilang ekonomista na bilang kinahinatnan nito, ang mag-aaral sa Estados Unidos ay magpapatuloy sa kanilang pag-aaral sa tagalagas ng 2020 na may humigit kumulang $70 \%$ ng mga natamo sa pag-aaral na may kaugnayan sa karaniwang taon ng pag-aaral at ang mga natamo sa pagkatuto ay maaaring mas maliit pa sa matematika, na umabot lamang sa 50\%. kaya mahalaga para sa mga gumagawa ng patakaran sa edukasyon na maunawaan kung aling mga salik ang humadlang sa ilang mga bata na makatanggap ng sapat na pagkatuto kabilang sa kanila, bilang karagdagang sa kakulangan ng mga alituntunin sa kurikulum ng mga elementong ito ay natukoy din ang isang malaking pagkakaiba- iba sa mga paaralan at bansa.

Sa kalidad ng online na pag-aaral na nagpapataas ng alalahanin na ang pagkakaiba sa mga resulta ng edukasyon sa buong "socio-economic" na grupo ay maaaring mapalakas sa kawalan ng mga hakbang sa pagwawasto. Alinsunod sa Estados Unidos mahigit isang-katlo ng mga mag-aaral ang ganap na hindi kasama sa online na pag-aaral, partikular sa mga paaralang may malaking bahagi ng mga mag-aaral na mababa ang koita habang ang mga "elite" na pribadong paaralan ay nakaranas ng halos buong pagpasok gayundin, ang ebidensya mula sa England (United kingdom) ay nagmumungkahi ng mga bata mula sa mas mayamang pamilya ay gumugol ng 30\% na mas maraming oras sa pag-aaral sa bahay kaysa sa mga mula sa mas mahirap na pamilya sa panahon ng lockdown, at nag-ulat na mas nakakaramdam sila ng suporta kaysa sa sosyo-ekonomikong mga magulang na may kapansanan. Habang ang mga mag-aaral mula sa mas mayaman na paaralan ay may access sa mas indibidwal na mga mapagkukunan (tulad ng online na pagtuturo o pakikipag-chat sa mga guro).

Alinsunod sa Divina Law (dynamic lawyering) habang ang mga paaralan ay kasalukuyang nananatiling sarado sa mga lugar na nasa ilalim ng community quarantine, ang mga educator ay bumaling sa online na pag-aaral at iba pang "flexible learning system" upang matiyak ang kaligtasan ng mga stakeholder sa panahon ng pandemya. Ginagamit ng mga sistemang ito ang teknolohiya at iba pang malikhaing pamamaraan bilang alternatibo sa tradisyonal, nakabatay sa silid-aralan na pag-aaral sa pagsisikap na angkop sa tinatawag na new normal. Noong Disyembre 9, 2014, nilagdaan na bilang "Open Distance Learning Act”, upang palawakin at higit pang idemokrasiya ang access sa dekalidad na tersiyaryong edukasyon at teknikal na serbisyong pang edukasyon sa bansa sa pamamagitan ng bukas na mga serbisyo sa pag-aaral ang online na pag-aaral ay nagtatanghal ng maraming benepisyo, ang mga naturang pakinabang ay limitadong teknolohiya sa isang pahayag, kinilala ng CHED na $20 \%$ lamang ng estado ng mga unibersidad at kolehiyo sa buong bansa ang may kagamitan sa buong bansa ang may kagamitan sa mga online classes sa gitna ng krisis sa coronavirus, kaya naman nilinaw ng CHED na ang “flexible learning”ay hindi mahigpit na tumutukoy sa purong online na system.

Flexible learning materials na hindi nakadepende sa internet tulad ng mga take-home na aktibidad at "learning packet" na isusumite sa pag-alis ng quarantine. Ang parehong gabay na prinsipyo ay nalalapat sa mga programang pang-degree na nangangailangan ng internship at mga pagsasanay sa mag-aaral. Halimbawa: para sa mga programang pang-degree na nangangailangan ng internship at mga klinikal na tungkulin tulad ng medisina, nursing, at mga kaalyado ng programang pangkalusugan, ang naaangkop na alternatibo ng mga platform. Sa pag-aaral ay maaaring gamitin ng mga AELS (e.g., electronic at non. Electronic na mga pamamaraan sa pag-aaral, simulation, case based scenario, at iba pa) kapalit ng kinakailangang oras ng pakikipag-ugnayan para makamit ang mga resulta ng kurso / mga resulta ng programa, kabilang ang pagsusuri at pagtatasa ng mga kakayahan sa pagtuturo.

Para sa mga programang pang-degree tulad ng accountancy, engineering, hospitality management,computer studies, industriyal na teknolohiya at iba pang mga programang hindi nauugnay sa kalusugan, mga alternatibong aktibidad na ginagawa ng mga estudyante trainer sa mga opisina/laboratories ay bahagi ng portfolio na sinusumite ng mga pagsasanay (CHED COVID Advisory No. 6, na inilabas noong 13 Abril, 2020) Ang ibang 
mga institusyong pang-edukasyon kabilang ang mga grade school at mataas na paaralan ay nagpapatupad ng mga pangunahing hakbang mula sa batas at iniangkop ang pareho sa kanilang ibat ibang pangangailangan at kakayahan. Bukod pa rito, inihayag ng edukasyon na isinasaalang-alang nila ang paggamit ng radyo at telebisyon para sa pagpapakalat ng mga materyal na pang-edukasyon bilang pagkilala sa katotohanan na hindi lahat ng mga mag-aaral ay may access sa kompyuter at internet. Ayon kay Nelson Mandela, ang kalidad ay hindi isang aksidente, ito ay palaging resulta ng matalinong pagsisikap dapat tayong maging isa sa pagbuo ng mga solusyon upang matugunan ang puwang na nilikha ng pandemya at malampasan ang mga hadlang sa pag-access sa dekalidad na edukasyon. Sapagkat pagkatapos ng pandemya, tiyak na magbubunga ang ating puhunan sa edukasyon ng mga kabataan sa pagtiyak ng kinabukasan ng bansang ito.

\subsection{Paglalahad ng Suliranin}

Ang pananaliksik na ito ay nabuo upang matukoy ang online learningsa panahon ng pademya sa taong panuruan 2021-2022. Ang mga mananaliksik ay nag lalayon na masagot ang mga sumusunod na katanungan:

$>$ Ano-ano ang impak ng online learning sa mga mag aaral?

$>$ Ano-ano ang mga salik na nakakaapekto sa online learning?

$>$ Ano-ano ang mga rekomendasyon batay sa nabuong resulta ng pag-aaral?

\section{Pamamaraang ginamit}

Disenyo ng pananaliksik - An pamamaraang ginamit sa pananaliksik ay deskripto kung saan ipinakita ng mga mananaliksik ang pag lalarawan at pag bibigay linaw ng mga datos mula sa mga mag-aaral na sa secondarya na paaralan na saklaw ng dalawang punong guro at limang pung mag-aaral ng secondarya patungkol sa online learning.

Paraan ng pag likom ng datos - Isa sa mga stratehiya na ginagamit sa pananaliksik na ito ay ang pagsusurbey ang pag susurbey ay ginawa gamit ang pag bibigay ng mga tanong sa mga piling estudyante na nasa SHS kasama na din ang ilang guro ang surbey ay tungkol sa online learnig ang suliranin an gaming nabuo ay galling sa din ang kanilang kaalaman pang teknolohiya kaonlinelearning ang edukasyon baga man walang harapan (face to face) sa ngayon ngunit nalilinang mga nakalap naming na impormasyon.

Instrumento - Gamit ang suliranin ito kami ay nakabuo ng mga tanong patungkol sa kung pano mapapanghawakan ng mga guro ang pag tutoro ng birtwal na klase at sa mga mag aaral na kung ano ang kanilang karanasan patungkol sa birtwal na klase na nakasulat sa surbey. Nakatulong ang pag susurbey upang higit na malaman kung paano na iimpluwensyahan ang mga mag-aaral ng SHS ang patungkol sa panahon ng pandemya. Sa ganitong resulta ng pagkakalap ng datos na pag alaman ng aming grupo at dapat na maimungkahi muna sa mag-aaral na ang kasanayang online class ay para sa ganon tuloy parin ya walang dapat ika bahala at ikatakot sapagkat ayun sa mga panayam at sagot ng mga guro handa sila maibigay ang abot ng kanilang makakaya para may matutunan ang mga bata.

Frequency distribution - Sa mga problema sa mga gamit para sa kanilang pag-aaral online may mga ahensya na sa ngayon maging ito ay pribado o sa gobyerno na handang tumulong para sa gagamitin ng mag-aaral. Higit sa lahat ang pag iisip ng positibo na ang pag-aaral online ay hindi pa sakit kundi tulong para sa kinabukasan at tinatawag na new normal sa larangan ng edukasyon. Maging bukas sa opinyon, pag sagot sa mga tanong, at higit sa lahat ang makatao at makadiyos na pag gabay sa mga bata upang kanilang maisapuso at isip na ang online class ay sagot sa krisis na hinaharap dahil sa kailangan ang ibayung pag iingat. 


\section{Mga Natuklasan}

\section{Talahanayan 1}

Negatibong impak ng online learning

\begin{tabular}{lll}
\hline \multicolumn{1}{c}{ Negatibo } & Bilang & Rango \\
\hline 1.Nag kakaroon ng stress ang mga mag -aaral na walang gadgets at internet sa online learning & 25 & 5 \\
2. Ang mga pag-ganap na gawain ng limitado dahil sa birtwal ang pag aaral & 10 & 9 \\
3. Hindi maipaliwanag ang mga aralin & 35 & 3 \\
4. Mas maliit ang mga makukuhang impormasyon anag mga mag aaral & 40 & 2 \\
5. Walang pambili ng mobile phone o pamabayad sa data & 15 & 8 \\
6. Bumababa ang motibasyon ng mga mag-aaral & 25 & 6 \\
7. Nag kakaroon ng mental stress ang mag-aaral & 30 & 4 \\
8. Kakaunti lamang ang natututunan at naiintindihan ng mag-aaral . & 20 & 7 \\
9. Nahihirapang mag komplay ang mag-aaral sa mga aktibidad sa paaralan. & 45 & 1 \\
10.Madalas ang pag liban dahil walang internet at cellphone & 5 & 10 \\
\hline
\end{tabular}

Masasalamin sa Talahanayan 1 ang bilang ng mga mag-aaral na sumasang-ayon sa mga paglalarawan ukol sa negatibong dulot ng online learning. Batay sa talahanayan ang may pinakamataas na rango ay ang hirap ng pag komplay ng mag-aaral sa mga aktibidad sa paaralan samantalang ang may pinakamamabang rango ay ang bilang sampo ito ang madalas napagliban dahil sa walang internet connection. ayon din sa mga eksperto ang online learning ay nag reresulta sa mental stress sa mga bata na nawalan ng opotunidad na makipag kaibigan dahil laging computer ang kaharap nadedebelop sa bata ang pag kamasarili nahihirapang makipag ugnayan sa kapwa at nangingibabaw sa isip na maari naman siyang mabuhay mag isa at hindi kailangan ang iba. May isa pang nakakalungkot na bunga ang online learning ang online kopyahan kayab humihingi na ng tulong ang DepEd sa law enforcement upang matukoy at mahinto ang ganitong pandaraya. Marahil kailangan na ring mag karoon ng reorientation sa mga bata at magulang sa tunay na layunin ng edukasyon at ito ang matuto upang maging mabuti at kapaki pakinabang na mamamayan ng bansa. Hindi ang pag kakaroon ng mataas na grado at karanalan ang tunay na layunin ng edukasyon.

\subsection{Positibong impak ng online learning}

\section{Talahanayan 2}

Positibong impak ng online learning

\begin{tabular}{lcc}
\hline \multicolumn{1}{c}{ Positibo } & Bilang & Rango \\
\hline 1.Sinasanay nito ang mag-aaral na maging responsable sa sariling pag katuto & 20 & 8 \\
2. Nagagamit sa mahusay na paraan ang modernong teknolohiya & 10 & 10 \\
3. Kahit online learning ay nakakapag-aral & 30 & 7 \\
4.Mas magagabayan tayo ng ating magulang dahil di natin kailangang lumabas & 50 & 1 \\
5.Mas ligtas kapag online learning. & 45 & 3 \\
6. Natututo ang mga mag-aaral na pamahalaan ang kanilang mga gawain at oras. & 45 & 6 \\
7. Nakakamura sa tuition . & 50 & 5 \\
8. May pag kakataon ang mag-aaral na makapag pahinga . & 40 & 4 \\
9. May pag kakataong makatulong sa gawaing bahay at sa magulang & 20 & 9 \\
10. May pag kakataong makapaghanap buhay o makapag trabaho. & & \\
\hline
\end{tabular}

Ayon sa talahanayan ang may pinakamataas na bilang ay ang may pag kakataong mag-aral at makapagpahinga, nakakuha naman ng sumunod na bilang ng sumang-ayon ay ang ligtas kapag online learning na may bilang na 45. Masasalamin na marami parin ang natutuwa sa dulot ng online learning. Ayon kay Centeno De Jesus may positibong epekto naman ang pag-aaral ng online learning may mga benipisyong katulad ng pag kakaroon ng disiplina ng mga estudyante sa pag babalanse ng kanilang pag-aaral, paggawa sa mga gawain bahay at pag kakaroon ng oras para sa pamilya. Dagdag pa rito dahil sa online learning mas maagang natutunan ng mga estudyante kung paano umangkop sa isang sitwasyon na nakakatulong sa kanila sa reyalidad kapag sila ay nakapag trabaho na. 
Jazo, K. M., Borlagdan, J., Fernicol, J., Rivero, J., \& Gelilio, E.

\subsection{Salik na nakakaapekto sa online learning}

\section{Talahanayan 3}

Salik na nakakaapekto sa online learning

\begin{tabular}{lcc}
\hline \multicolumn{1}{c}{ Salik na nakakaapekto sa online learning } & Bilang & Rango \\
\hline 1.Kawalan ng internet & 40 & 3 \\
2. Kawalan ng kagamitan tulad ng telepono (mobile phone) computer/loptop & 10 & 9 \\
3. Kawalan ng komunikasyon sa guro & 20 & 7 \\
4. Pag litawan ng online games & 40 & 2 \\
5. Maingay na paligid & 30 & 5 \\
6. Gulo ng mga kasama sa bahay & 35 & 4 \\
7. Mga tamabak na gawaing bahay & 45 & 1 \\
8. Sabay-sabay na eskedyul tulad ng duty sa trabaho at eskedyul ng online class & 25 & 6 \\
9. Sabay-sabay na gawain at deadline & 15 & 8 \\
10. Trabahong hindi maaaring iwanan o ipagpaliban & 5 & 10 \\
\hline
\end{tabular}

Ipinapakita sa talahanayan 3 na ang karamihan sa mga mag-aaral na may responde na may bilang na 40 at rangong 3 na ang salikna nakakaapekto sa online learning ay kawalan ng internet access dahil sa kawalan naman ng kagamitan tulad ng telepono /computer/loptop mahihirapan silang makipag komunikasyon sa mga online learning at sa pag unawa ng mga takdang aralin na sinagutan naman na may bilang na 10 at sa rangong 9, dahil sa kawalan ng komunikasyon sa guro nahihirapan ang mga estudyante na unawain ang mga aralin sa sagutan naman na may bilang 20 at 7 na rango. Tugon naman ng ilang mag-aaral na may bilang na 40 at 2 rangona may isang salik na mas nakakaapekto sa pag-aaralay ang pag litawan ng online games ito ay mas nakakabahala para sa mga mag-aaralay ang adiksyon nito at kawalan ng control sa paggamit ng tamang oras at ginugogol sa pag lalaro kaysa sa pag-aaral .Batay rin sa hinaing ng mga mag-aaral na may bilang 30 at 5 rango nakakasagabal din ang maingay na paligid, gulo ng mga kasama sa bahay na pinunaan ng ilang estudyante na may bilang 35 at 4 na rango.

Samantala bilang 45 at 1 rango ang mga tambak na Gawain bahay ito ang mga dahilan kung bakit nawawalan ng konsentrasyon sa pag-aaral. Samantala ang may bilang na 25 at 6 na rango ang sabay sabay na eskedyul tulad ng duty sa trabahon at eskedyul ng oline class nahihirapan silang pag hati-hatiin ang oras sa trabaho at pag-aaral, kasabay na rin ang pag habol ng deadline sa pag pasa at Gawain bahay na sianagutan ng may bilang 15 at 8 rango, habang nasa limang bilang at 10 rango na trabahong hindi maaring iwanan o ipagliban.ito ay batay sa datos na nakalap ng aming grupo sa pananaliksik sa ibat ibang dahilan sa mga salik na nakakaapekto sa online learning ng aming kapwa mag-aaral. Ayon naman sa pag-aaral na isinulat ni Allan Ortiz na batay sa frame work for 21 st century ng learning ang mga tao sa ng ika-21 na siglo ay nasasanay sa kabuhayang teknolohiya at media drism dahil dito sa pag sasanay o kinalakihan ng mga kabataan sila ay makakakuha ng mga impormasyong sa madaling paraan.

\subsection{Rekomendsyon batay sa nabuong resulta ng pag-aaral}

Ipinapakita sa Talahanayan ang mga rekomendasyon na maaaring gawin upang maging mabisa ang online learning. Nasa 50 ang bilang ng mga sumang-ayon sa Magtanong-tanong o humingi ng update sa mga kamag-aral o guro patungkol sa aktibidad sa online classes at ito ay nasa unang ranngo. Mabisa itong paraan dahil may mga bagay ding ginagawa ang mga estudyante sa kani-kanilang bahay kaya kung minsan ay hindi agad nila nalalaman ang mga gawain sa birtwal na pag-aaral. 50 din ang sumang-ayon sa Unahin ang mga aktibitis bago ang iba na kung saan ito naman ang nasa pangalawang ranggo. Karamihan sa mga mag-aaral ay naaagaw ng ibang bagay ang kanilang atensyon na sana ay ilaan nila ito sa pag-aaral. Nasa ikatlong ranggo naman ang Humingi ng alternibong paraan sa mga guro upang makagawa at maipasa ang mga aktibidad sa online classes na kailangang tapusin. Epektibo ito sapagkat makakatulong upang maging produktibo ang mga mag-aaral na gawin ng tama sa oras ang mga gawain at maaaring makatulong pa din sila sa mga gawaing bahay kapag natapos na ang mga gawain sa paaralan. 


\section{Talahanayan 4}

Rekomendsyon batay sa nabuong resulta ng pag-aaral

\begin{tabular}{lcc}
\hline \multicolumn{1}{c}{ Rekomendasyon batay sa nabuong resulta ng pag-aaral } & Bilang & Rango \\
\hline 1.Makipagkoordinasyon sa mga guro kasama ang magulang. & 40 & 5 \\
2. Gawing ng maaga ang mga gawain bago ang online class & 35 & 6 \\
3. Gumawa ng listahan ng mga gawain na nag lalaman ng mga kailangang gawin at tapusin sa loob ng & 30 & 7 \\
isang araw & 30 & 8 \\
4. Makiusap sa amo o pinagtatrabahoan o mag hanap ng trabaho na maipag sasabay sa pag aaral . & 9 \\
5. Pakiusapan ang mga kasama sa bahay na tulongan ka sa pag aaral sa paraan ng hindi pag iinngay at & 25 & 4 \\
pag tulong saiyo sa mga gawaing bahay. & 45 & 3 \\
6. Humingi ng alternatibong paraan sa mga guro upang makagawa at maipasa ang mga aktibidad sa & 20 & 10 \\
online classes na kailangang tapusin. & 50 & 1 \\
7. Makisabay sa iisang account ng kamag-aral tuwing dadalo ng online classes. & 40 & 4 \\
8. Mag tanong-tanong o humingi ng update sa mga kamag-aral o guro patungkol sa aktibidad sa & 50 & 2 \\
online classes & & 4 \\
9. Mag hanap o lumipat sa lugar na tahimik at doon gumawa ng aktibidad sa online classes. & & \\
10. Unahin ang mga skul aktibitis bago ang iba. & & \\
\hline
\end{tabular}

\section{Kongklusyon}

$>\quad$ Buhat ng mag simula ang pandemyang dulot ng COVID 19, mag kahalong positibo at negatibong impak ang nararanasan ng mag-aaral ng bayan ng Irosin.

$>\quad$ Nangibabaw ang positibong impak ng pandemya sa mag-aaral ng bayan ng Irosin batay sa surbey na sinagutan ng piling kalahok.

$>\quad$ Mas nagging kakaiba ang pag harap ng mga mag-aaral sa makabagong estratihiyang pang-edukasyon na nag dududlot ng kawalan ng pocus, stress, pag kabalisa, pag kataranta at over thinking sa mga mag-aaral.

$>\quad$ Isang malaking parte upang mas maging mainam ang pag katuto ng mga mag-aaral sa kabila ng hinaharap na pandemya ang pag gabay at pag tulong ng mga magulang at mga guro.

\subsection{Rekomendasyon}

\section{$>\quad$ Maging bukas sa opinion}

$>\quad$ Maging makatao at makadiyos na pag gabay ng magulang sa mga bata upang isapuso at isa isip na ang online learning ay isang daan upang maitaguyod at malampasan ang krisis na dala ng pandemya.

$>\quad$ Mag karoon ng pakikipag ugnayan sa mga guro at ahensya ng baranggay

$>\quad$ Mag sa gawa ng blended type of learning upang mabigyan ng pag kakataon ang ibang mag-aaral na walang kagamitan upang makipagsabayan sa online learning.

> Mag karoon ng mas malalim na pag sisiyasat ukol sa mas epektibong paraan upang mabigyan ang lahat ng mag-aaral ng pag kakataon na maabot ang angkop na estratehiya ng edukasyon.

\section{Talasanggunian}

Bullo, M. (2021). Integration of video lessons to Grade-9 science learners amidst COVID-19 pandemic.

International Journal of Research Studies in Education, 10(9), 67-75. https://doi.org/10.5861/ijrse.2021.670

Burggess, S. (2020). How should we help the COVID 19 cohorts make up the learning loss from lockdown? Retrieved from https://committees.parliament.uk/writtenevidence/6381/default/

Castroverde, F., \& Acala, M. (2021). Modular distance learning modality: Challenges of teachers in teaching amid the Covid-19 pandemic. International Journal of Research Studies in Education, 10(8), 7-15. 
Jazo, K. M., Borlagdan, J., Fernicol, J., Rivero, J., \& Gelilio, E.

https://doi.org/10.5861/ijrse.2021.602

Ching, G. S., \& Roberts, A. (2020). Evaluating the pedagogy of technology integrated teaching and learning: An overview. International Journal of Research Studies in Education, 9(6), 37-50.

https://doi.org/10.5861/ijrse.2020.5800

Hanushek, E., \& Woessmann, L. (2020). The economics impacts of learning losses. Education Working Papers. OECD Publishing. https://doi.org/10.1787/21908d74-e

Llaneta, R. N. (2021). COVID-19 pandemic: Hamon sa kahandaan ng mga irosanong gurong magulang sa paaralan at tahanan. International Journal of Research Studies in Education, 10(4), 79-91. https://doi.org/10.5861/ijrse.2021.622

UNESCO. (2020). COVID-19 educational disruption and response. https://en.unesco.org/covid/educationresponse 